\title{
A comparative study of the effects of gastrin, histamine, histalog, and mechothane on the secretory capacity of the human stomach in two normal subjects over 20 months
}

\author{
G. M. MAKhlouf, J. P. A. McMANUS, AND W. I. CARD \\ From the Gastrointestinal Unit, Western General Hospital, Edinburgh, \\ and the Department of Medicine, University of Edinburgh
}

EDITORIAL SYNOPSIS This is an exhaustive study of the basal and stimulated secretion of two normal subjects over a period of 20 months. The calculated maximal responses have been experimentally obtained by slow intravenous administration of massive doses of gastrin II. These studies have enabled many characteristics of gastric activity to be defined.

The gastric secretory acid responses to 'maximal' stimulation by histamine or gastrin II administered subcutaneously have previously been studied in normal individuals and ulcer patients (Makhlouf, McManus, and Card, 1964a). The dose-response of a normal subject to a series of continuous infusions or to graded single intravenous injections of gastrin II have also been reported (Makhlouf, McManus, and Card, 1964b).

The present paper is an extension of these studies. The secretory responses of two normal male subjects, G.M. and J.M., have now been examined over a period of 20 months. The experiments were designed to determine the pattern of secretory response in time to various gastric stimulants, singly or in combination; and the relationship of the responses of the two subjects. In a study of this kind, two important parameters against which all data are to be interpreted must first be established with sufficient accuracy, namely, a base line respresenting the spontaneous secretion, and the maximal response of the stomach which, it will be shown subsequently, is defined by the value of the asymptote of the doseresponse curve following stimulation by intravenous gastrin. The first section will deal with the way in which these parameters are established.

\section{METHODS}

The procedures have already been described in our previous communications. Three points, however, are worthy of re-emphasis.
1 Salivary contamination was prevented by the insertion of dental cotton pledgets in the sulci of the cheeks.

2 The juice was collected every five minutes and pooled into samples corresponding to 10 -minute periods for purposes of titration, except in the case of single intravenous injections of gastrin, when five-minute samples were estimated directly.

3 The 'pumping' effect of deep respiration is of major importance in the accurate collection of juice over short periods, and it was used throughout.

In the early experiments, the spontaneous secretion was collected for one hour. As the subjects became conditioned to the procedure, it was found that a 20-minute collection, accurately recorded, provided a sufficient indication of the spontaneous secretion.

All the tests, often repeated, were performed in a random manner over a period of 20 months. Fifty tests involving administration of gastrin II by infusion or single intravenous injection were performed, and were equally distributed between the two subjects.

The range of doses delivered by continuous infusion was 0.2 to $90 \mu \mathrm{g}$. $/ \mathrm{hr}$. In the case of single intravenous injections of gastrin, the range was 0.5 to $100 \mu \mathrm{g}$. total dose. In earlier experiments using this latter technique, insufficient attention had been paid to the standardization of the time during which the dose was delivered. In subject GM, however, whose dose-response curve is shown here, doses below $5 \mu \mathrm{g}$. were administered over one minute. Higher doses were given more slowly.

Four additional tests, two on each subject, were performed in which histamine $(40 \mu \mathrm{g} . / \mathrm{kg} . / \mathrm{hr}$.$) or$ histamine $(20 \mu \mathrm{g} . / \mathrm{kg} . / \mathrm{hr}$.) plus mechothane $(3 \mathrm{mg} . / \mathrm{hr}$.) were infused in doses known to elicit a 'maximal' response from this stimulant (Lawrie, Smith, and Forrest, 1964). 


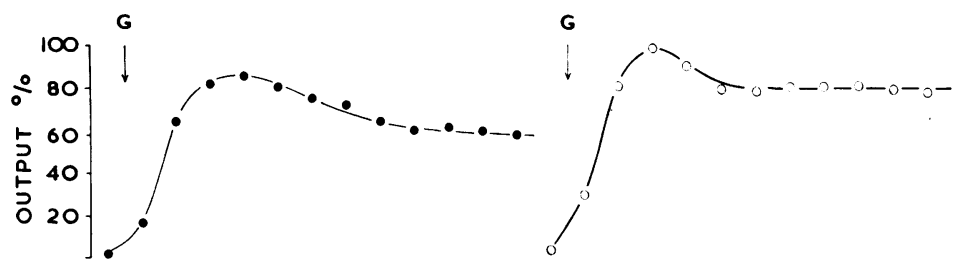

FIG. 1. Time-output relationship following maximal infusion of histamine (40 $\mu \mathrm{g} . / \mathrm{kg} . / \mathrm{hr}$.) and a nearmaximal infusion of gastrin

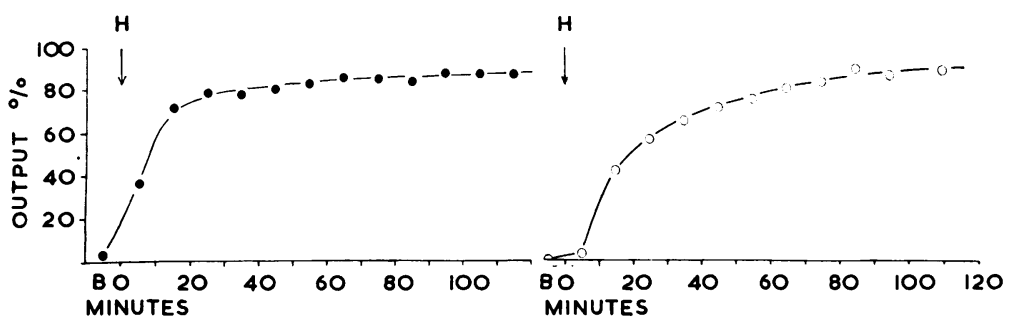
$(0 \cdot 8-1 \cdot 1 \mu \mathrm{g} . / \mathrm{kg} . / \mathrm{hr}$.$) in subject$ G.M. and subject J.M. $\bigcirc$. Outputs are expressed for purposes of comparison as percentages of the respective calculated maximal response.

Fifty mg. of mepyramine maleate was given 20 minutes before the start of the histamine infusions.

Thirty-seven collections of spontaneous secretion ('basal') were also taken from subject G.M. and 18 from subject J.M.

\section{RESULTS}

The results are summarized in Tables I and II and Figures 1, 2, and 3.

CONTINUOUS INFUSIONS OF (1) GASTRIN AND (2) HISTAMINE The time-output relationship following stimulation by continuous infusion of gastrin has been described. The acid output first rises to a peak lasting 20-40 minutes, depending on the size of the dose, and is then followed by a more steady response. Figure 1 illustrates this characteristic. The response to histamine or to histamine plus mechothane shows a distinct difference in this respect. The peak is only attained after some considerable time, usually around the end of the second hour. This slow rise is more evident in the response of subject J.M. This difference between gastrin and histamine is clearly of import-

\section{TABLE I}

PEAK RESPONSE IN MEq./hr. FOLLOWING THE ADMINISTRATION OF SINGLE INJECTIONS OF GASTRIN II (SUBJECT G.M.)

\begin{tabular}{|c|c|c|c|}
\hline Date & $\begin{array}{l}\text { Intravenous } \\
\text { Dose ( } \mu g .)\end{array}$ & Log-Dose & $\begin{array}{l}\text { Peak Output } \\
\text { (mEq./hr.) }\end{array}$ \\
\hline 9. 3.65 & $1 \cdot 10$ & 0.040 & $8 \cdot 4$ \\
\hline 23. 2.65 & $2 \cdot 15$ & 0.332 & $14 \cdot 6$ \\
\hline 9. 2.65 & 3 & 0.477 & $17 \cdot 2$ \\
\hline $\left.\begin{array}{l}18.1 .65 \\
18,12.64\end{array}\right\}$ & 4 & 0.602 & $20 \cdot 7$ \\
\hline $\begin{array}{c}8.12 .64\} \\
9.12 .63\end{array}$ & $10 \cdot 40$ & 1.017 & $29 \cdot 2$ \\
\hline 3. 1.64 & $27 \cdot 50$ & 1.439 & $34 \cdot 2$ \\
\hline 3. 4.64 & 100 & 2.000 & $36 \cdot 0$ \\
\hline
\end{tabular}

\section{TABLE II}

MAXIMAL RESPONSES OF SUBJECTS G.M. ${ }^{1}$ AND J.M. ${ }^{1}$ FOLLOWING VARIOUS MODES OF ADMINISTRATION OF GASTRIN, HISTAMINE, HISTALOG, SINGLY OR IN COMBINATION WITH EACH OTHER OR WITH MECHOTHANE

$\frac{\text { Output per Hour }}{\text { GM JM }}$

Percentage of Calculated Maximal Response

\begin{tabular}{lll}
\hline$G M$ & $J M$ & Mean \\
\hline 100 & 100
\end{tabular}

Ratio GM/JM

Calculated maximal response infusion

Calculated maximal response intravenous gastrin

50-100 $\mu \mathrm{g}$. intravenous gastrin

Maximal subcutaneous gastrin

Maximal subcutaneous gastrin + maximal subcutaneous histamine

Maximal subcutaneous gastrin + mechothane subcutaneously

Maximal histamine infusion

$\frac{1}{2}=$ maximal histamine infusion + mechothane

Maximal subcutaneous histamine + mechothane subcutaneously

Maximal subcutaneous histamine

Histalog, 200 mg., subcutaneously

$\begin{array}{ll}36 & 54 \\ 36 & 54 \\ 36 & 54 \\ 32 \cdot 9 & 49 \cdot 1 \\ 32 \cdot 4 & 50 \cdot 8 \\ 31 \cdot 2 & 51 \\ 31 \cdot 5 & 48 \cdot 2 \\ 31 \cdot 7 & 46 \cdot 6 \\ 31 \cdot 4 & 44 \cdot 2 \\ 25 \cdot 1 & 38 \cdot 8 \\ 28 \cdot 2 & 42 \cdot 5\end{array}$

100
100
100
$91 \cdot 4$
90
$86 \cdot 5$
$87 \cdot 5$
88
87
70
$78 \cdot 5$

100
100
100
91
94
$95 \cdot 4$
89
$86 \cdot 5$
82
72
$78 \cdot 6$

$\begin{array}{cl}100 & 66 \cdot 6 \\ 100 & 66 \cdot 6 \\ 100 & 66 \cdot 6 \\ 91 & 67 \\ 92 & 64 \\ 91 & 61 \\ 88 \cdot 5 & 65 \cdot 5 \\ 87 & 68 \\ 84 & 71 \\ 71 & 65 \\ 78 \cdot 5 & 66 \cdot 5\end{array}$

${ }^{1}$ G.M. weighed 64 kg. and J.M. 82 kg. 


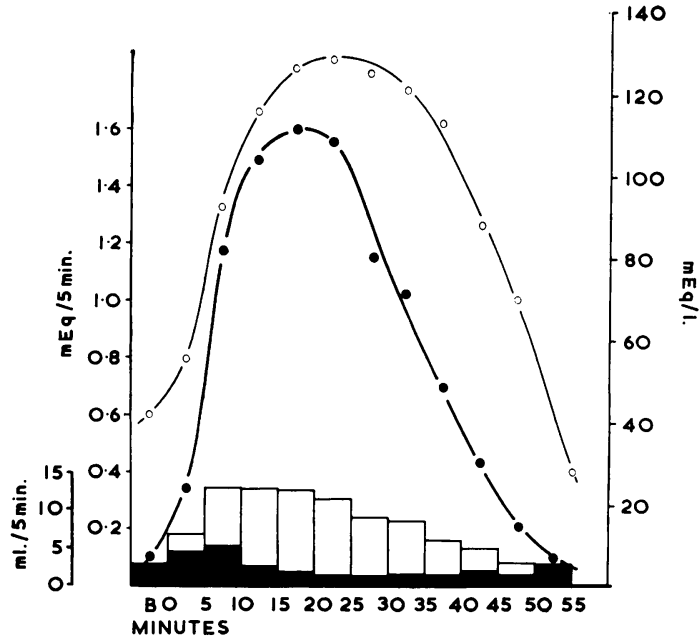

FIG. 2. Output in mEq./5 min., secretory rate in ml./5 min., and $\mathrm{H}^{+}$ion concentrations following an intravenous injection of gastrin (4 $\mu$ g.) in subject G.M. The secretory rate is divided into its parietal and non-parietal (blacked-out portion) components.

ance when maximal responses from the two stimulants are being compared.

INTRAVENOUS INJECTION OF GASTRIN Figure 2 shows the characteristics of the response to a single intravenous injection of gastrin $(4 \mu \mathrm{g}$.). The secretory rate, acid output, and hydrogen ion concentration achieved their peaks in this order. This is because the volume in the first two or three samples following stimulation is to a large extent of non-parietal origin. As can be seen in Fig. 2, frequent sampling (in this case at five-minute intervals) allows a good estimate
This peak response is calculated from the peak 10-minute output, i.e., the sum of the two consecutive five-minute peak outputs. All results are expressed as the peak output per hour through multiplication by six.

The response of subject J.M. to graded single intravenous injections of gastrin has been reported elsewhere (Makhlouf et al., 1964b). The plot of the peak response against the logarithm of the corresponding dose was linear. It was suggested that this probably represented the linear portion of a sigmoid dose-response curve. By careful standardization of the duration of injection of a dose, it has now been possible to confirm this fact. A fit to a logistic function of the peak responses for subject G.M. against log-dose is shown in Figure 3.

THE CALCUlated MAXIMAL RESPONSE The logistic function which was chosen represents a model in which molecules of a secretory stimulant form addition complexes with a number of secretory units. When a sufficiently high dose of the stimulant is given, all secretory units available for activation are considered to be secreting. This theoretical level of secretion is represented by the asymptote of the sigmoid dose-response curve. Since by implication the secretory unit mass is related to the parietal cell mass, the value of the asymptote gives us an index of the latter.

The maximal responses calculated from the asymptotes of the dose-response curves following single intravenous injections of gastrin are 36 and 54 $\mathrm{mEq}$./hr. for subjects G.M. and J.M. respectively, and are subsequently referred to as the calculated maximal responses. These are identical with the calculated maximal responses for dose-response L' curves using continuous infusion of graded doses of

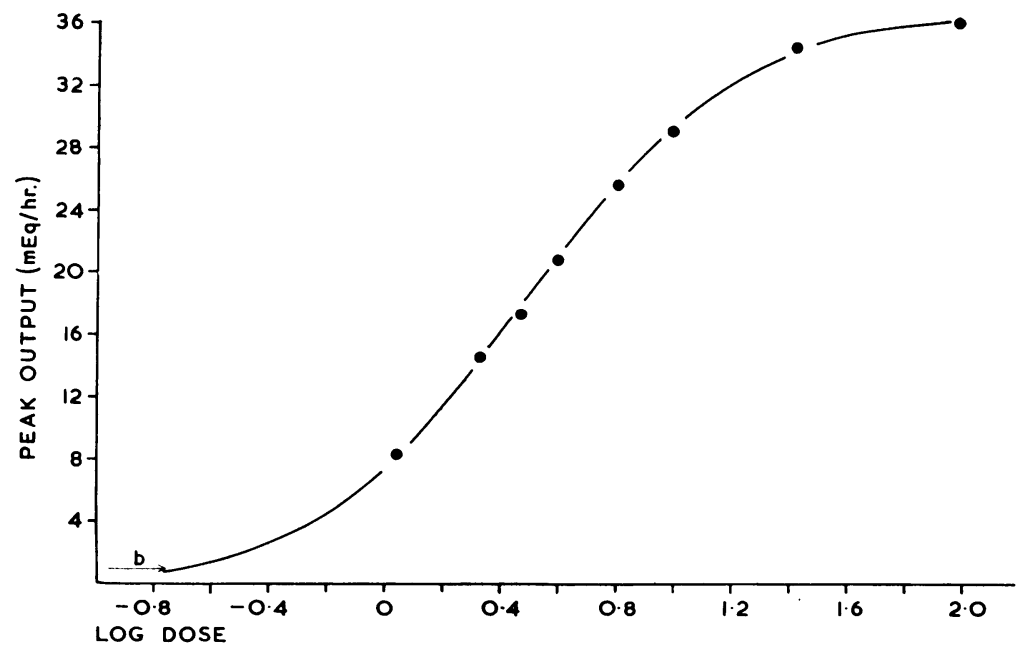

FIG. 3. Dose-response curve following single intravenous injections of gastrin II (subject G.M.). 
gastrin II. These calculated maximal responses have, moreover, been experimentally attained in both subjects over periods of 10 to 20 minutes by slow administration of single massive intravenous doses of gastrin II (50 to $100 \mu \mathrm{g}$.), and in all probability represent the maximal secretory capacity of the normal intact human stomach to stimulation. No other stimulant or combination of stimulants could be found that would induce a higher response. For purposes of comparison, all data in this and the subsequent section are expressed as percentages of the calculated maximal responses of each subject, which are thus taken to be $100 \%$.

In contrast to the effect of intravenous gastrin, the highest response to maximal infusion of histamine is $87.5 \%$ and $89 \%$ in subjects G.M. and J.M. respectively (mean $88.5 \%$ ). By maximal infusion is meant that dose $(40 \mu \mathrm{g} . / \mathrm{kg}$. $/ \mathrm{hr}$.) which elicits the highest possible peak response from histamine delivered by continuous infusion. The response to infusion of half the dose of histamine $(20 \mu \mathrm{g} . / \mathrm{kg} . / \mathrm{hr}$. plus mechothane $(3 \mathrm{mg} . / \mathrm{hr}$.) is $88 \%$ and $86.5 \%$ in subjects G.M. and J.M. respectively (mean $87 \%$ ), and is indistinguishable from the response to the higher doses of histamine alone. Both, however, fall short of the maximal calculated response to gastrin.

SPONTANEOUS SECRETION This study offered the unusual opportunity to study the pattern of spontaneous secretion over a prolonged period in two normal individuals conditioned to the procedure. In subject G.M., a spontaneous acid secretion in 37 samples collected over a period of 20 months oscillated over a narrow range: $0.88 \mathrm{mEq} . / \mathrm{hr}$. \pm S.D. 0.34. Eighty per cent of the figures are within \pm 1 S.D. The minor variations in spontaneous acid output probably reflect similar variations in background vagal tone or circulating gastrin, or small errors of collection.

During the first year of testing, the behaviour of the spontaneous secretion in subject J.M. was similar to that outlined above for subject G.M. During this period, the mean acid output of nine collections was $1.35 \mathrm{mEq} . / \mathrm{hr}$. \pm S.D. 0.25 . Nine further collections were taken over the next eight months, none of which contained any acid. The average volume of these collections was $22.5 \mathrm{ml}$./ $\mathrm{hr}$. \pm S.D. $5 \cdot 1$, their $p \mathrm{H}$ ranged between 7 and 8 , and on three occasions when it was tested for, the bicarbonate concentration was $1 \cdot 2,6 \cdot 8$, and $9 \cdot 3$ $\mathrm{mEq}$./l. respectively.

This absence of acid secretion may represent a distinct diminution of background vagal tone to very low levels, since a $5 \mathrm{mg}$. dose of mechothane administered during a 'basal' period usually, though not invariably, resulted in acid secretion of around $3 \mathrm{mEq}$./hr.

The ratio of the mean spontaneous acid output of subject G.M. to that of subject J.M. during the period when the latter still secreted acid spontaneously was $66 \%$, that is, a ratio identical to the ratio of their calculated maximal responses. For both subjects, the spontaneous acid output was $2.5 \%$ of their respective calculated maximal response.

\section{DISCUSSION}

Two important parameters can thus be defined on the basis of these findings, namely, the base line as represented by a reproducible and near-constant spontaneous secretion in a conditioned test subject, and the secretory capacity of the intact human stomach as represented by the calculated maximal response to intravenous administration of gastrin.

The maximal response to continuous infusion of histamine is around 87 to $88 \%$ of the calculated maximal response to continuous infusion of gastrin. This is in very close agreement with the data reported for ulcer patients and normal subjects using maximal subcutaneous doses of gastrin or histamine, where the ratio was $87 \%$ (Makhlouf et al., 1964a).

The ratios of the maximal responses of subject G.M. to subject J.M. are around $66 \%$ in every case. It will be shown in the subsequent section that this ratio holds independently of the stimulant, combination of stimulants used, or mode of administration, and in all probability represents the ratios of their respective parietal cell masses.

It is interesting to note from the dose-response curves how very potent is gastrin II when given in a single intravenous injection (Fig. 3). Thus the administration of a total of $1 \mu \mathrm{g}$. intravenously to subject G.M. (wt. $64 \mathrm{~kg}$.) results in a peak response which is around $20 \%$ of the calculated maximal response. If the level of circulating gastrin is responsible for the spontaneous secretion $(0.88 \mathrm{mEq} . / \mathrm{hr}$., i.e., $2.5 \%$ ) of the intact human stomach, it must be of a very low order.

From data on the amount of gastrin extractable from a human antrum (Lai, 1964) and the evidence of the dose-response curve, it is conceivable that the post-prandial response to endogenous release of gastrin achieves, at least for a time, near-maximal levels.

SECTION II

In this section, the observations are extended by the use of gastrin, histamine, histalog, and mechothane, 
administered subcutaneously or intramuscularly, singly or in combination.

\section{METHODS}

Whenever histamine was used, it was preceded 20 minutes before by the intramuscular injection of $100 \mathrm{mg}$. of mepyramine maleate. Unless stated otherwise, mechothane (carbaminoyl B-methyl choline chloride) or atropine was administered subcutaneously 20 minutes before the start of a test.

The doses used were those known to induce a 'maximal' response from a particular stimulant under a certain mode of administration. Thus for (a) gastrin, maximal response is obtained following the administration of $2 \mu \mathrm{g} . / \mathrm{kg}$. subcutaneously and probably $1 \mu \mathrm{g}$. $/ \mathrm{kg}$. intramuscularly (Makhlouf et al., 1964a); (b) for histamine, $40 \mu \mathrm{g} . / \mathrm{kg}$. subcutaneously (Kay, 1953); (c) for betazole hydrochloride (histalog), $200 \mathrm{mg}$. subcutaneously (Ward, Gillespie, Passaro, and Grossman, 1963).

The following series of tests was performed:(1) Gastrin, $2 \mu \mathrm{g} . / \mathrm{kg}$. subcutaneously, or $1 \mu \mathrm{g} . / \mathrm{kg}$. intramuscularly; (2) histamine, $40 \mu \mathrm{g}$. $/ \mathrm{kg}$. subcutaneously (3) histalog, $200 \mathrm{mg}$. subcutaneously; (4) gastrin, $2 \mu \mathrm{g}$. $/ \mathrm{kg}$. subcutaneously plus histamine, $40 \mu \mathrm{g} . / \mathrm{kg}$. subcutaneously, administered simultaneously; (5) gastrin, $2 \mu \mathrm{g} . / \mathrm{kg}$. subcutaneously plus mechothane, $5 \mathrm{mg}$. subcutaneously, and gastrin, $2 \mu \mathrm{g}$. $/ \mathrm{kg}$. subcutaneously plus mechothane administered by continuous infusion in a dose of $3 \mathrm{mg}$./ hr. throughout the test (subject G.M. only); (6) histamine, $40 \mu \mathrm{g} . / \mathrm{kg}$. subcutaneously plus mechothane $5 \mathrm{mg}$. subcutaneously; and (7) gastrin, $2 \mu \mathrm{g}$. $/ \mathrm{kg}$. subcutaneously plus atropine, $0 \cdot 6 \mathrm{mg}$. subcutaneously.

Smaller doses of histamine, gastrin, and mecothane in various combinations were also used to test for potentiatory effects and will be described in the appropriate sections.

All the tests, often repeated, were performed in random manner over a period of 20 months. Thirty-eight tests were performed, equally distributed between the two subjects.

\section{RESULTS}

The 'maximal' responses following subcutaneous or intramuscular injection were calculated from the peak 20-minute output, i.e., the sum of the two consecutive 10-minute periods giving the highest output, and are expressed as the output per hour through multiplication by three. Thus, the term 'maximal subcutaneous response to gastrin', for example, refers to the highest possible response obtained following administration of a dose of $2 \mu \mathrm{g} . / \mathrm{kg}$. of gastrin subcutaneously, a dose previously shown to be a maximal dose for that mode of administration; and similarly for other stimulants, or combinations of stimulants.

The results are summarized in Table II.

It will be noted that the response to maximal subcutaneous or intramuscular gastrin is $91 \%$ of the calculated maximal response. The responses to the simultaneous administration of maximal subcutaneous gastrin and maximal subcutaneous histamine are 90 and $94 \%$ respectively for subjects G.M. and J.M. (mean $92 \%$ ) and are similar to the response following maximal subcutaneous gastrin alone. Similarly, the response to maximal subcutaneous gastrin plus mechothane, subcutaneously or by infusion, is 86.5 and $94.5 \%$ respectively in subjects G.M. and J.M. (mean $91 \%$ ) and is virtually indistinguishable from the response to maximal subcutaneous gastrin alone.

The response to maximal subcutaneous histamine alone is 70 and $72 \%$ (mean $71 \%$ ) and is less than the response to maximal subcutaneous gastrin alone. The response to maximal subcutaneous histamine plus mechothane is 87 and $82 \%$ respectively in subjects G.M. and J.M. (mean $84 \%$ ) and is distinctly higher than the response to maximal subcutaneous histamine alone but still lower than the response to maximal subcutaneous gastrin alone.

\section{DISCUSSION}

MAXIMAL SUBCUTANEOUS GASTRIN Figure 4 shows the acid output following administration of $2 \mu \mathrm{g} . / \mathrm{kg}$.

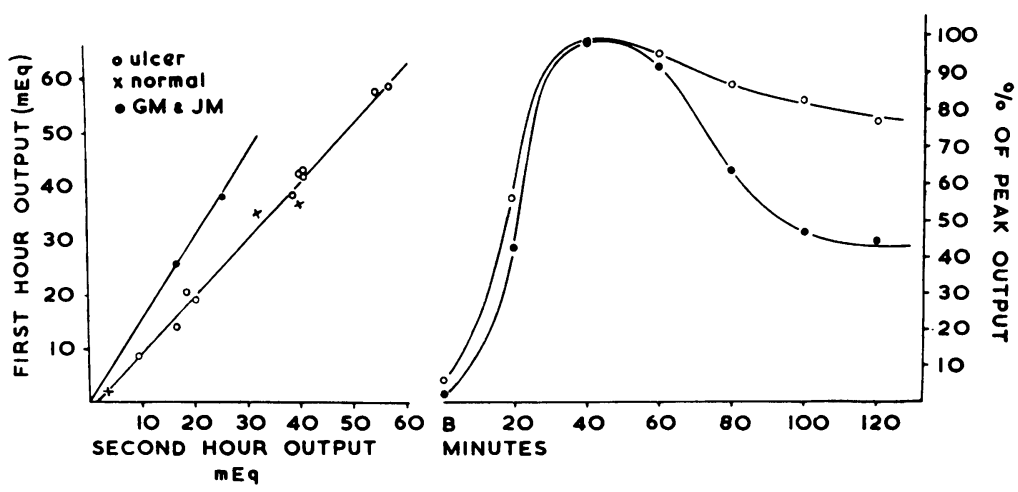

FIG. 4. Relationship between the outputs of the first and the second hours in normal subjects and ulcer patients tested for the first time $(r=0.994, n=13)$ as compared with the conditioned subjects G.M. and J.M. (left). Time-output relationship for ulcer patients and subjects G.M. and J.M. following subcutaneous injection of gastrin, $2 \mu \mathrm{g} . / \mathrm{kg}$. (right). The curves are drawn for comparison as percentages of the respective peak outputs of each group. 
of gastrin. The upper curve represents the mean response of 10 ulcer patients and is drawn as a percentage of their mean peak output, which occurs, as for normal subjects, in the middle 20-minute period of the first hour. The lower curve is derived from the responses of subjects G.M. and J.M. Both curves follow a similar course during the first hour but the fall during the second hour is more evident in the normal conditioned test subjects, with low constant or absent spontaneous secretion.

It has been noted (unpublished data) that repeated observations on the spontaneous secretion tended to show a progressive fall as the test subject, patient or normal volunteer, became conditioned to the test procedure. The curves of normal volunteers other than subjects G.M. and J.M., tested for the first time, approximate to the upper curve. Similarly, administration of mechothane to subjects G.M. and J.M., though it had no effect on the peak response, which occurred during the first hour, tended to shift the shape of the curve upwards during the second hour to approximately the same level as the upper curve. One possible explanation may be in the different background vagal tone of subjects tested for the first time. This would tend to keep the response to the falling level of gastrin during the second hour at a higher level.

A striking linear relationship exists between the response of the first and second hours, in ulcer patients and normal subjects tested for the first time $(r=0.994, n=13)$. The difference outlined above, which exists between conditioned normal subjects, and normal subjects and ulcer patients tested for the first time, is shown graphically in Figure 4.
HISTAMINE PLUS GASTRIN The effect of histamine appears to be synergistic with the effect of gastrin at lower dose levels. Thus, in subject G.M. the response to maximal subcutaneous histamine plus $0.25 \mu \mathrm{g} . / \mathrm{kg}$. of gastrin subcutaneously was higher than the response to maximal subcutaneous histamine alone. When, however, the maximal subcutaneous dose of gastrin was administered simultaneously with either the maximal or half the maximal subcutaneous dose of histamine, the response was not higher than that elicited by maximal subcutaneous gastrin alone.

It can thus be concluded that for subcutaneous administration, (a) the response to $2 \mu \mathrm{g} . / \mathrm{kg}$. of gastrin probably represents a real maximum and cannot be increased by the simultaneous administration of subcutaneous histamine; (b) submaximal responses can be raised to near maximal when both stimulants are administered simultaneously; (c) the response to maximal subcutaneous histamine does not represent the maximal secretory capacity of the stomach under that mode of administration, since it can be further raised by appropriate doses of gastrin.

HISTAMINE PLUS MECHOTHANE That the response to maximal subcutaneous histamine does not represent the maximal capacity of the stomach is further confirmed by the effect of mechothane on this dose of histamine (Fig. 5). In both subjects, the maximal response for the combined effect of the two stimulants was raised from a mean of $71 \%$ with histamine alone to one of $84 \%$ with histamine plus mechothane. This level is now almost equal to that follow-
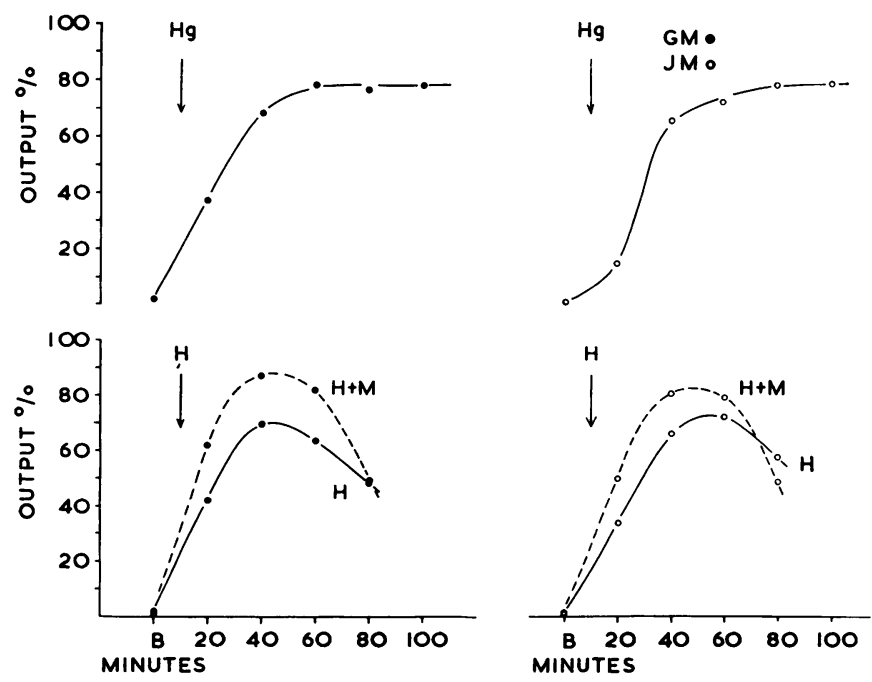

FIG. 5. Time-output relationship in subject G.M. and J.M. $\bigcirc$ after subcutaneous histamine, $40 \mu \mathrm{g} . / \mathrm{kg}$. $(\mathrm{H})$; subcutaneous histamine, $40 \mu \mathrm{g} . / \mathrm{kg}$. plus subcutaneous mechothane, $5 \mathrm{mg}$. $(H+M)$; and subcutaneous histalog, $200 \mathrm{mg}$. (Hg.). The outputs for each 20 minutes are drawn as percentages of the respective calculated maximal response of each subject. 
ing maximal infusion of histamine, or infusion of histamine plus mechothane (Section I).

The time of appearance of the peak is of great importance in comparing responses. This fact is well illustrated in Figs. 1 and 5, and shows a consistent difference in this respect between subjects G.M. and J.M. With subcutaneous histamine and histalog and histamine infusion the rise of the response and the achievement of the peak is more rapid in subject G.M. That this could well be due to the difference in background vagal tone is suggested by the following two considerations:-(1) In contrast to subject G.M., the spontaneous secretion collected from subject J.M. before these tests did not contain any acid; (2) when subcutaneous mechothane was administered before the administration of subcutaneous histamine, the rise of the peak response was now more rapid in subject J.M. and was achieved at the same time as for subject G.M. (Fig. 5).

HISTALOG The maximal responses to subcutaneous administration of $200 \mathrm{mg}$. of histalog agree with the data reported for man by Ward et al. (1963). It will be noted that the histalog response is higher than the subcutaneous maximal histamine response but lower than the peak response following continuous infusion of histamine or histamine plus mechothane, or even subcutaneous histamine plus mechothane.

GASTRIN PLUS MECHOTHANE Several technical difficulties seemed to render testing the combined effect of gastrin and mechothane by infusion in man difficult to achieve. It has already been shown
(Makhlouf et al., 1964b) that the response to infused gastrin is biphasic. A peak response precedes a near steady state, the former rising earlier, more sharply, and falling more rapidly as the infused dose increases. A similar type of response, as well as a dose-reversal phenomenon at the highest dose, has been reported in dogs following infusion of urecholine (Gillespie and Grossman, 1964).

Cholinergic stimulation appears to have a relatively minor effect on the response of the intact human stomach to gastrin. Thus, the peak response to intravenous injection of $4 \mu \mathrm{g}$. of gastrin is $57 \%$ of the calculated maximal response and is raised a further $10 \%$ by prior administration of $5 \mathrm{mg}$. of mechothane. In contrast, a similar dose of mechothane administered before the test, or an infusion of mechothane $(3 \mathrm{mg}$./ $/ \mathrm{hr}$.) throughout the test, had no effect on the maximal subcutaneous response to gastrin.

It thus appears that, whereas simultaneous cholinergic stimulation tends to potentiate the peak response to a submaximal intravenous dose, it has no noticeable effect on the response to maximal subcutaneous gastrin. It will be recalled, however, that a similar dose of mechothane raised the maximal subcutaneous histamine response by nearly $13 \%$.

Lin and Ivy (1957) found that a similar situation as for gastrin obtained with stimulation of pancreatic secretion by secretin. Whereas simultaneous cholinergic stimulation potentiated the effect of small doses of secretin, it had no effect on the maximal response which could be elicited by the administration of a large dose of secretin alone. With

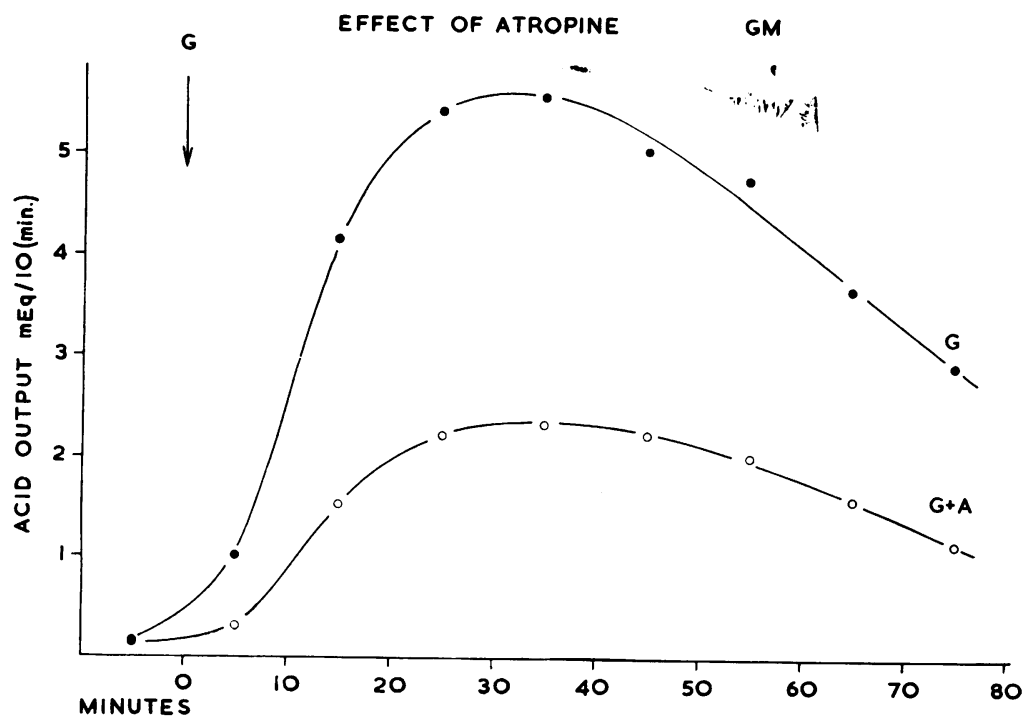

FIG. 6. Effect of subcutaneous atropine $(0.6 \mathrm{mg}$.) on the maximal subcutaneous response to gastrin (2 $\mu \mathrm{g} . / \mathrm{kg}$.) in subject G.M. 
regard to salivary secretion, eserine and other anticholinesterases increased the secretory response to lower doses of acetylcholine but were without effect on the maximal response achieved by acetylcholine alone (Beznák and Farkas, 1937; Burgen, Keele, and Slome, 1949; Burgen and Emmelin, 1961). One has to contend here, however, with the fact that in the final analysis the effects of exogenous acetylcholine and eserine are not easily distinguishable.

GASTRIN AND ATROPINE A similar dose of atropine, $0.6 \mathrm{mg}$., administered subcutaneously before the administration of a maximal subcutaneous dose of gastrin reduced the peak responses by 20 and $60 \%$ respectively in subjects J.M. and G.M. (Fig. 6). No attempt to relate the dose of atropine to body weight was made. This, however, confirms earlier reports by Gregory and Tracy (1961), that a dose of $1.2 \mathrm{mg}$. intramuscularly of atropine virtually abolishes the response to a submaximal dose of gastrin in man.

AN ACTIVE SYNTHETIC PENTA-PEPTIDE Gregory and Tracy (1964) described the physiological properties of synthetic derivatives representing various portions of the total gastrin molecule. Among these was the penta-peptide $\mathbf{Z} \cdot$ Gly·Try $\cdot$ Met $\cdot$ Asp $\cdot$ Phe $\cdot \mathbf{N H}_{2} \cdot(\mathrm{Z}=$ $\left.\mathrm{C}_{6} \mathrm{H}_{5} \cdot \mathrm{CH}_{2} \cdot \mathrm{O} \cdot \mathrm{CO}\right)$. We have found that this substance is a less potent stimulant of acid secretion than

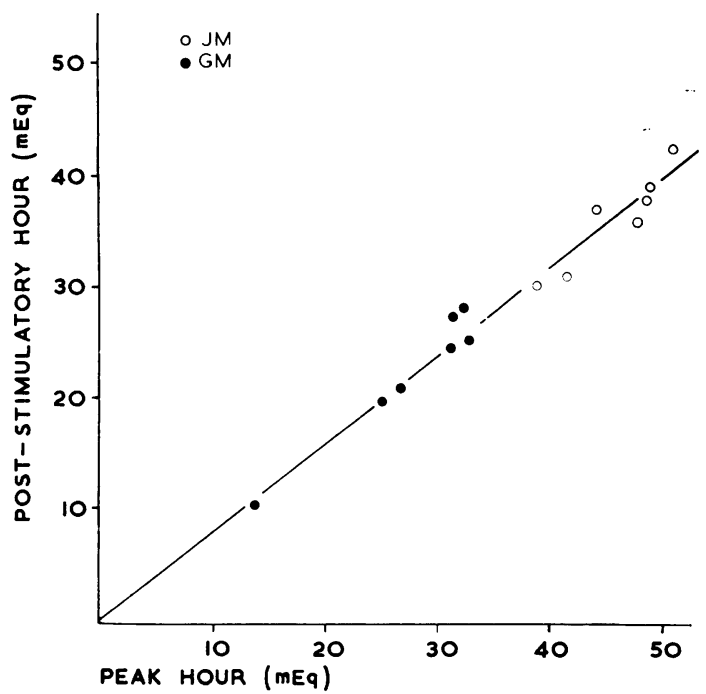

FIG. 7. Relationship between the peak hour and the poststimulatory hour outputs in milliequivalents following maximal subcutaneous gastrin and histamine, singly or in combination with each other or with mechothane. gastrin II on the human subjects studied. The peak response following administration of $4.5 \mu \mathrm{g} . / \mathrm{kg}$. subcutaneously in G.M. was $40 \%$ of the calculated maximal response to gastrin II. Doubling the dose raised the response by a further $10 \%$.

PEAK AND FIRST HOUR OUTPUTS The results obtained here by repeated tests under various conditions confirm our previous report (Makhlouf et al., 1964a) that the peak and first hour outputs following maximal stimulation by gastrin or histamine are correlated linearly. Maximal stimulation by various combinations of stimulants does not appear to alter this relationship (Fig. 7). Only occasionally there appears to be a delay in the rise of secretion during the first 20 minutes, reducing the level of the poststimulatory hour, but remaining without effect on the level of the peak hour.

SECRETORY RATE AND $\mathrm{H}^{+}$ION CONCENTRATION In contrast to our previous report where small differences in the hydrogen ion concentrations of the histamine and gastrin juices were masked by patients swallowing saliva, the present findings, where great pains were taken to avoid contamination, show a slight tendency for histamine and histalog juice to be more limpid and of higher concentration. As has been shown, mechothane may or may not raise the acid output according to the combination of stimulants used. In nearly every case, however, the volume output increased, the $\mathbf{H}$ ion concentration decreased, while the sodium output and concentrations were raised. The implications of this finding will be discussed in a subsequent communication.

RELATIONSHIP OF THE RESPONSES OF THE TWO SUBJECTS The ratio of the responses of subject G.M. and subject J.M. is again and in every case around $66 \%$, except when mechothane was administered, when it was slightly higher with histamine and slightly lower with gastrin. This ratio is an index of the sizes of their respective parietal cell masses. As estimate of this on the basis of calculations provided by Shay (1959) would give 1 and $1.5 \times 10^{9}$ cells for subjects G.M. and J.M. respectively.

This near-constant ratio, besides indicating the consistent pattern of response in the two subjects over a period of 20 months, points to the important fact that responses can only be compared under identical modes of stimulation. Maximal stimulation, implying as it does stimulation of all available secretory units following a certain mode of administration, introduces a standard situation for purposes of comparison. 
The demonstrable difference between the response of the intact human stomach to gastrin and histamine does not necessarily indicate an intrinsic difference in the response of the parietal cell to these stimulants. Similar differences have been encountered in the rat following stimulation by gastrin and histamine (Kahlson, Rosengren, Svahn, and Thunberg, 1964; Adashek and Grossman, 1963). If it becomes accepted that gastrin acts by releasing histamine, then, as Kahlson points out, the difference may represent an intracellular mobilization of histamine in proximity to the receptor sites, thus achieving a higher local concentration than is possible with histamine reaching the secretory cell from the outside.

The kinetics of transport and elimination of drugs vary with the mode of administration. Subcutaneous administration of gastrin may not achieve equivalent local tissue concentrations, and this may provide an explanation for the somewhat lower responses achieved under this mode of administration. It, nevertheless, bears a constant relation to the maximal calculated response following infusion of gastrin.

Before it can be finally accepted that cholinergic stimulation increases the 'sensitivity' of the acidsecreting cells to stimulation, attention must be given to the effect of cholinergic influences on gastric blood flow, and consequently, on delivery of the stimulant to the active sites of secretion. The possibility that cholinergic stimulation by its effect on the intrinsic muscular tone of the stomach may release histamine locally by deformation of the amine-containing cells (enterochromaffin and mast cells) (Paton and Vane, 1963), or that it may facilitate access of the stimulant to intracellular sites, must also be borne in mind.

SECRETORY TESTS It has been noted that simultaneous cholinergic stimulation does not appear to alter the subcutaneous maximal response to gastrin but has a distinct effect on the 'maximal' subcutaneous response to histamine. Fluctuations in background vagal tone would tend to induce parallel fluctuations in the peak response to histamine, but not in that to gastrin. This would add a further advantage to the use of subcutaneous gastrin in estimating the secretory capacity of the intact human stomach which, with its freedom from sideeffects and the absence of any need of an antihistamine, renders it ideally suited for this purpose.

ANTIBODIES To GASTRIN At the close of this series of tests, the sera of both subjects were tested for the presence of antibodies to gastrin II by a sensitive method developed by Ganguli and Hunter, and were found to be entirely free (personal communication).

\section{SUMMARY AND CONCLUSIONS}

The spontaneous secretion and the responses of two normal subjects over a period of 20 months to stimulation by gastrin, histamine, histalog, with or without mechothane, and administered by various means, have been studied. A total of 86 tests was performed. In addition, 55 collections of spontaneous secretion were estimated.

1 Dose-response curves for the effect of gastrin II administered by continuous infusion or by single intravenous injections on the acid output of the intact human stomach have been constructed and show a good fit to a logistic function. The calculated maximal responses corresponding to the value of the asymptote of the dose-response curves (height parameter) are the same whether continuous infusion or single intravenous injections are used. These maximal responses have been experimentally attained by the slow intravenous administration of massive doses of gastrin II, and probably represent the maximal capacity of the human stomach to stimulation. No other combination of stimulants with or without gastrin could be found that would induce a higher response from the stomach.

2 When gastrin is administered subcutaneously, the maximal response is around $91 \%$ of the calculated maximal response and is higher than the response to maximal subcutaneous histamine or to histalog alone.

3 A synergistic effect exists between histamine and gastrin at the lower dose levels. However, the response to combinations of the maximal subcutaneous gastrin dose with the maximal or half the maximal subcutaneous histamine dose does not exceed the response to maximal subcutaneous gastrin alone.

4 Simultaneous cholinergic stimulation is effective in potentiating the response to small doses of gastrin, and appears to be without effect on the peak response achieved by maximal subcutaneous gastrin alone.

5 In contrast, the peak response to subcutaneous histamine is distinctly raised by simultaneous cholinergic stimulation to a level very near that achieved by infusion of histamine or histamine plus mechothane. The peak response to histamine infusion is not exceeded by an infusion of histamine and mechothane in combination. This response to infused histamine probably represents the maximal response of the stomach to exogenous histamine, and is still less than the maximal calculated response to gastrin.

6 Atropine has a distinct inhibitory effect on the maximal subcutaneous response to gastrin.

7 Repeated estimations of spontaneous secretion 
numbered altogether 55 in the two subjects over a period of 20 months. They demonstrate the near constancy of the spontaneous response of the stomach under truly basal conditions in subjects conditioned to the procedure.

The evidence from the spontaneous output and the dose-response curves suggests that the level of circulating gastrin during fasting in man is of a very low order.

Similar evidence from the dose-response curves and from data on gastrin extracted from human antra suggests that the post-prandial response to endogenous gastrin may well, at least initially, attain near-maximal levels.

8 A distinct relationship is evident under all experimental conditions between the two subjects, namely, the fixed ratio of their responses under similar conditions of maximal stimulation. It is suggested that this constant ratio, independent of the mode through which maximal stimulation is achieved whether by single stimulants or combinations of stimulants, represents the sole discriminating parameter, namely, the respective parietal cell masses of the two subjects.

We should like to express our gratitude to Professor R. A. Gregory for his valuable advice and his generous gift of gastrin II. We are indebted to Professor G. W. Kenner of the Department of Organic Chemistry, the University of Liverpool, for making available to us a specially purified sample of the penta-peptide for these experiments. We should also like to thank Professor R. B. Fisher, Dr. W. Sircus, and Dr. C. G. Thomson for their helpful criticism, and Miss Irene Newlands for technical assistance. The procedures were carried out in the Teaching and Research Centre, Western General Hospital, Edinburgh. This work was supported by a grant from the Medical Research Council.

\section{REFERENCES}

Adashek, K., and Grossman, M. I. (1963). Responses of rats with gastric fistulas to injection of gastrin. Proc. Soc. exp. Biol. (N.Y.), 112, 629-631.

Beznák, M., and Farkas, E. (1937). The interpretation of some phenomena of salivary secretion caused by direct electrical stimulation of the effector nerve in terms of the present knowledge of the nervous impulse and of its chemical transmission. Quart. J. exp. Physiol., 26, 265-283.

Burgen, A. S. V., and Emmelin, N. G. (1961). Physiology of the Salivary Glands, p. 140. E. Arnold, London.

- Keele, C. A., and Slome, D. (1949). Pharmacological actions of tetraethylpyrophosphate and hexaethyltetraphosphate. $J$. Pharm. Pharmacol., 96, 396-409.

Ganguli, P. C., and Hunter, W. M. (Personal communication). Gillespie, I. E., and Grossman, M. I. (1964). Potentiation between Urecholine and gastrin extract and between Urecholine and histamine in the stimulation of Heidenhain pouches. Gut, 5 , 71-76.

Gregory, R. A., and Tracy, H. J. (1961). The preparation and properties of gastrin. J. Physiol. (Lond.), 156, 523-543.

- _ - (1964). Physiological properties of a series of synthetic peptides structurally related to gastrin I. Nature (Lond.), 204, 935-938.

Kahlson, G., Rosengren, E., Svahn, D., and Thunberg, R. (1964). Mobilization and formation of histamine in the gastric mucosa as related to acid secretion. J. Physiol. (Lond.), 174, 400-416.

Kay, A. W. (1953). Effect of large doses of histamine on gastric secretion of $\mathrm{HCl}$ : an augmented histamine test. Brit. med.J., 2, 77-80.

Lai, K. S. (1964). Studies on gastrin. Part II. Quantitative study of the distribution of gastrin-like activity along the gut. Gut, 5, 334-336.

Lawrie, J. H., Smith, G. M. R., and Forrest, A. P. M. (1964). The histamine-infusion test. Lancet, 2, 270-273.

Lin, T. M., and Ivy, A. C. (1957). Relation of secretin to the parasympathetic mechanism for pancreatic secretion. Amer. J. Physiol., 189, 361-368.

Makhlouf, G. M., McManus, J. P. A., and Card, W. I. (1964a). The action of gastrin II on gastric acid secretion in man. Lancet, 2 , 485-490.

- $-1,-1964 b)$. Dose-response curves for the effect of gastrin II on acid gastric secretion in man. Gut, 5, 379-394.

Paton, W. D. M., and Vane, J. R. (1963). An analysis of the responses of the isolated stomach to electrical stimulation and to drugs. J. Physiol. (Lond.), 165, 10-46.

Shay, H. (1959). Emotional stress and parietal cell mass. Amer. J. dig. Dis., N.S., 4, 846-870.

Ward, S., Gillespie, I. E., Passaro, E. P., and Grossman, M. I. (1963). Comparison of histalog and histamine as stimulants for maximal gastric secretion in human subjects and in dogs. Gastroenterology, 44, 620-626. 